The Humane Society Institute for Science and Policy

Animal Studies Repository

2017

\title{
Physiological and behavioural evaluation of common anaesthesia practices in the rainbow trout
}

Kieran C. Pounder

University of Liverpool

Jennifer L. Mitchell

University of Liverpool

Jack S. Thomson

University of Liverpool

Tom G. Pottinger

Lancaster Environment Centre

Lynne U. Sneddon

University of Liverpool

Follow this and additional works at: https://animalstudiesrepository.org/aneana

Part of the Animal Studies Commons, Other Animal Sciences Commons, and the Veterinary Toxicology and Pharmacology Commons

\section{Recommended Citation}

Pounder, Kieran C.; Mitchell, Jennifer L.; Thomson, Jack S.; Pottinger, Tom G.; Sneddon, Lynne U. 2018. Physiological and behavioural evaluation of common anaesthesia practices in the rainbow trout. 199. 94-102. https://doi.org/10.1016/

j.applanim.2017.10.014 
Article (refereed) - postprint

Pounder, Kieran C.; Mitchell, Jennifer L.; Thomson, Jack S.; Pottinger, Tom G.; Sneddon, Lynne U. 2018. Physiological and behavioural evaluation of common anaesthesia practices in the rainbow trout.

(C) 2017 Elsevier B.V.

This manuscript version is made available under the CC-BY-NC-ND 4.0 license http://creativecommons.org/licenses/by-nc-nd/4.0/ (c) EY-NC-ND

This version available http://nora.nerc.ac.uk/518815/

NERC has developed NORA to enable users to access research outputs wholly or partially funded by NERC. Copyright and other rights for material on this site are retained by the rights owners. Users should read the terms and conditions of use of this material at http://nora.nerc.ac.uk/policies.html\#access

NOTICE: this is the author's version of a work that was accepted for publication in Applied Animal Behaviour Science. Changes resulting from the publishing process, such as peer review, editing, corrections, structural formatting, and other quality control mechanisms may not be reflected in this document. Changes may have been made to this work since it was submitted for publication. A definitive version was subsequently published in Applied Animal Behaviour Science (2018), 199. 94-102. https://doi.org/10.1016/j.applanim.2017.10.014 www.elsevier.com/

\section{Contact CEH NORA team at noraceh@ceh.ac.uk}

The NERC and CEH trademarks and logos ('the Trademarks') are registered trademarks of NERC in the UK and other countries, and may not be used without the prior written consent of the Trademark owner. 


\title{
Physiological and behavioural evaluation of common anaesthesia practices in the rainbow trout
}

Kieran C. Pounder ${ }^{1 *}$, Jennifer L. Mitchell ${ }^{1}$, Jack S. Thomson ${ }^{2}$, Tom G. Pottinger ${ }^{3}$ \& Lynne U. Sneddon ${ }^{1}$.

${ }^{1}$ Institute of Integrative Biology, University of Liverpool, Crown Street, Liverpool, L69 7ZB.

${ }^{2}$ School of Environmental Sciences, University of Liverpool, L69 3GP.

${ }^{3}$ Centre for Ecology \& Hydrology. Lancaster Environment Centre, Library Avenue, Bailrigg, Lancaster, LA1 4AP.

*Corresponding author: kpounder@liverpool.ac.uk.

\section{Highlights}

- We examined the effect of commonly used anaesthetics on behaviour and physiology of rainbow trout.

- Rainbow trout demonstrated low behavioural stress during immersion in 2-phenoxyethanol.

- Plasma cortisol concentrations were lowest in 2-phenoxyethanol treatment group.

- MS-222 administration had the most adverse stress response.

- 2-phenoxyethanol may be a preferred alternative anaesthetic for use in rainbow trout.

\begin{abstract}
Anaesthetic drugs are commonly administered to fish in aquaculture, research and veterinary contexts. Anaesthesia causes temporary absence of consciousness and may reduce the stress and/or pain associated with handling and certain invasive procedures. The rainbow trout (Oncorhynchus mykiss) is a widely-used model species with relevance to both aquaculture and natural ecosystems. This study sought to establish the relative acute impact of commonly used anaesthetics on rainbow trout when used for anaesthesia or euthanasia by exploring their effects on aversion behaviour and stress physiology. Five widely used anaesthetics were investigated at two concentrations reflective of common laboratory practises: MS-222, benzocaine, 2-phenoxyethanol, etomidate and eugenol. The anaesthetics were administered
\end{abstract}


via immersion and fish were: 1) euthanised with anaesthetic; or 2) allowed to recover from deep plane anaesthesia; or 3) subjected to a conditioned place avoidance paradigm. Behaviour, opercular beat rate and plasma cortisol concentrations and cortisol release rates to water were quantified to investigate the effects of the five drugs. Based upon longer induction to deep plane anaesthesia, and increased plasma cortisol levels post-anaesthesia the widelyused and recommended anaesthetic MS-222 may be relatively stressful for rainbow trout. Whereas 2-phenoxyethanol, due to a combination of quicker induction, reduced aversive behavioural response during anaesthesia and lower post-anaesthesia plasma cortisol levels may be a more advisable alternative. It is crucial for the welfare of fish that the use of anaesthetics is as humane as possible and thus these findings have important implications for the welfare and husbandry of captive rainbow trout.

Keywords: Oncorhynchus mykiss; Anaesthetic; 2-phenoxyethanol; Aversion; Stress; Cortisol.

\section{Introduction}

Fish are a major source of protein, with an estimated two million tonnes of farmed fish being produced across Europe annually (FEAP, 2014); they are also a widely exploited research model, second only to mice (e.g. UK Home Office, 2014; Europa 2015; USDA 2013), and they are a popular companion animal with large numbers kept in home aquaria, ponds and public aquaria (PFMA, 2015). The importance of safeguarding fish health and avoiding events that are aversive in the wide range of contexts in which fish are kept is essential. The administration of anaesthetics is employed during handling and experimental procedures in order to reduce stress, however, exposure to these drugs may in itself elicit a stress response thus it is vital that we know what the physiological and behavioural consequences of each drug are. Choice of humane anaesthetics in fish has been highlighted recently as an area of concern (Cressey, 2014).

The administration of anaesthetics to fish has long been widespread in veterinary practice, research and aquaculture (Schoettger and Julin, 1967) in order to minimise stress during procedures such as blood sampling, transportation, and routine veterinary surgery and consultation (Sneddon, 2012). Rates of induction and recovery have been investigated in previous studies, as have responses to external stimuli, and the pharmacokinetics of the 
anaesthetic agents (Sneddon, 2012). However, different species may react differently to, and tolerate, different anaesthetic drugs (Zahl et al. 2012). Previous research has been restricted to a limited number of species, with only a few anaesthetic agents investigated (Sneddon, 2012). Anaesthetics are usually administered to fish by immersion and simple awareness of the chemical can result in an aversive response or even a physiological stress response. Research by Readman, Owen et al. (2013) investigated whether nine of the most frequently used anaesthetic agents are perceived as aversive by zebrafish (Danio rerio) by exploring whether fish avoided water containing $50 \%$ of the effective concentration of each drug. In this study zebrafish actively avoided MS-222 (ethyl 3-aminobenzoate methanesulfonic acid) and benzocaine (ethyl 4-aminobenzoate), two of the most widely used anaesthetic agents (Sneddon, 2012; Readman et al. 2013). Least aversive of the agents tested in this study were etomidate [ethyl 3-(1-phenylethyl)imidazole-4-carboxylate] and 2,2,2 tribromoethanol (Avertin), and the authors recommended that etomidate should be favoured for routine zebrafish use (Readman et al. 2013). However, caution should be applied since etomidate possesses no pain relieving properties, and may actively interfere with the function of the stress axis (Limsuwan et al. 1983; Olsen et al. 1995), whereas MS-222 and benzocaine putatively act as local anaesthetics (Sneddon, 2012). Further evidence supporting the potential aversiveness of MS-222 has been reported in zebrafish which exhibited a greater condition place avoidance in response to MS-222 compared to eugenol (2-methoxy-4-prop-2enylphenol; clove oil, isoeugenol, AQUI-S $\left.{ }^{\circledR}\right)$ and metomidate [methyl 3-(1phenylethyl)imidazole-4-carboxylate] (Wong et al. 2014), and Lewbart (1998) describes an increase in excitatory behaviour including thrashing and leaping in response to MS-222 (species not specified). In contrast however, MS-222 had no effect post-treatment on several commonly measured behavioural parameters in zebrafish (Nordgreen et al. 2014). Many of these findings are specific to zebrafish, and there is a legitimate concern that the findings may not be applicable to other teleost species. This is evident in a study by Readman, Owen et al. (2017) who employed a chemotaxic choice chamber to ascertain if several closely related fish species responded differently when exposed to one of three anaesthetic agents, benzocaine, etomidate and MS-222. They found zebrafish (D. rerio), medaka (Oryzias latipes) and carp (Cyprinus carpio) all demonstrated avoidance behaviour to MS-222 and benzocaine, but not etomidate, whilst rainbow trout (Oncorhynchus mykiss) reportedly did not avoid any of the agents tested (Readman et al. 2017). Overall, there still remains a paucity of information on the non-target responses of fish to anaesthetics. 
The present study was conducted to investigate the effects of five commonly used anaesthetics each at two recommended concentrations for recovery anaesthesia and euthanasia. The acute effects on behaviour and physiology of rainbow trout (O. mykiss), a model species widely used in research (Thorgaard et al. 2002) were measured. The aims of the study were (i) to identify the most humane anaesthetic for euthanasia or anaesthesia with recovery, by measuring induction time to the onset of deep plane anaesthesia, time to the absence of consciousness and reflex responsiveness, and time to death and (ii) to identify the least behaviourally aversive anaesthetic using a condition place avoidance paradigm. In addition, the degree of stress associated with exposure to the anaesthetics was evaluated by measuring plasma cortisol concentrations in fish after mortality and one hour after recovery from deep plane anaesthesia.

\section{Materials and Methods}

\section{Fish husbandry}

Experiments were conducted with approval from the Home Office, U.K. (licence no. PPL 40/3435) and the University of Liverpool's Ethics Committee. Juvenile rainbow trout, Oncorhynchus mykiss $(n=103)$ were obtained from a commercial supplier and maintained in a stock tank ( $2 \times 2 \times 0.5 \mathrm{~m})$ in a semi-recirculating system at $12 \pm 1{ }^{\circ} \mathrm{C}$, with constant aeration and a 14:10 h light:dark cycle. The trout were allowed at least two weeks in the stock tank to recover from the stress of transport. Fish were fed commercial trout diet (Skretting, Northwich, U.K.) at $1 \%$ body weight per day. For experiments, fish were caught at random and transferred to separate individual glass aquaria $(90 \times 50 \times 45 \mathrm{~cm})$ in environmentally enriched conditions (air stone, gravel, plastic plant and an overhead area of cover). Each tank was screened to prevent visual disturbance. The glass aquaria were provided with filtered water and aeration by a semi-closed recirculation system and light, temperature and feeding regimes were identical to those of the stock tank. Fish remained in individual tanks for at least two weeks until acclimatised and were allowed at least seven days after resumption of feeding before use in experiments. Rainbow trout are a naturally territorial species and form dominance hierarchies where subdominants and subordinates are chronically stressed due to low social status (Gilmour et al., 2005; Sneddon et al., 2011). Therefore, this species is less stressed when held individually where they are allowed to form a "territory" within their holding tank without the stress of social subordination or territorial disputes (e.g. Frost et al., 2007; Thomson et al., 2011; 2012; Frost et al., 2013) thus we tested fish individually to ensure social stress was not a confounding factor and behaviour and physiological responses 
were consistent over the experimental period and any responses were due to the treatments imposed.

\section{Experiment 1: Euthanasia}

Fish (mean weight $\pm \mathrm{SE} ; 47.61 \pm 2.79 \mathrm{~g} ; n=31$ ) were randomly assigned to one of six treatment groups, five fish per group for benzocaine, etomidate, eugenol, MS-222 (buffered), 2-phenoxyethanol, and six fish for concussion (followed by exsanguination and pithing). For the anaesthetic treatments fish were carefully netted and removed from the tanks and placed in an opaque bucket with cover containing $10 \mathrm{~L}$ of aerated anaesthetic at the concentrations shown in Table 1 (Euthanasia). System water was used to ensure water quality parameters remained the same. Tachy opercular beat rate (OBR) and time to reach each of the following was measured for each fish: absence of equilibrium, low OBR, absence of reflex responsiveness to a tail pinch, absence of OBR, and death (Table 2). Fish were tested every $15 \mathrm{~s}$ for loss of responsiveness to tail pinch stimulus once loss of equilibrium and reduced OBR had been achieved. All measurements were conducted with partial cover over the bucket in order to avoid visual disturbance and minimise any stress to the fish. Death was confirmed by cessation of OBR and heart beat and the fish immediately exsanguinated. Two observers were present during the experiment, one who watched constantly and one who recorded the behaviours spoken by the first, to ensure results were consistent. The concussion treatment group were removed directly from their holding tanks and humanely killed by concussion. Blood samples were collected from each fish immediately following confirmation of death and assayed for cortisol as described below.

\section{Experiment 2 - Recovery from anaesthesia}

Fish (average weight \pm SE $138.17 \pm 5.77 \mathrm{~g} ; n=35$ ) were randomly assigned to one of seven treatment groups (five fish per group): benzocaine, etomidate, eugenol, MS-222, 2phenoxyethanol, sham handling and undisturbed. The sham handling group was included to account for the stress associated with the handling and relocation to the bucket, and the undisturbed group to control for when no manipulation occurred and fish remained in their individual holding tanks. Fish were carefully netted and removed from the individual holding tanks and placed in an opaque bucket with cover containing $10 \mathrm{~L}$ of aerated water with or

without (sham handling) anaesthetic at the concentrations shown in Table 1. The concentrations were chosen based on those recommended in Sneddon (2012), Neiffer and Stamper (2009), Ross and Ross (2008), reflecting those commonly used in laboratory practise 
for $O$. mykiss anaesthesia. The fish remained in the bucket until they reached deep plane anaesthesia, defined as the absence of responsiveness to a gentle tail pinch by forceps. Fish were tested every $15 \mathrm{~s}$ for loss of responsiveness to tail pinch stimulus once loss of equilibrium and reduced OBR had been achieved. For the sham treatment group the time spent in the bucket was established by averaging the time taken to establish deep plane anaesthesia in fish exposed to the five anaesthetics. System water was used in the buckets to ensure water quality parameters remained the same. From the time the fish were added to the bucket, to the point at which tail pinch responsiveness was lost, the fish were constantly monitored and assessed using a behavioural stress indicator scoring system (1-4): 1 = no movement; 2 = calm continuous swimming in the bucket with no breach of water surface; $3=$ sporadic erratic swimming where surface was breached in a rapid manner followed by being motionless; $4=$ constant erratic swimming where surface was breached during the entire induction period. Fish were assigned a stress score for the duration of exposure that represented the most severe indicator of behavioural stress observed. Time to absence of equilibrium and absence of a response to gentle tail pinch were also measured. Once the fish reached deep plane anaesthesia, they were returned to the home tank. They were left for 30 mins to recover, and then OBR was recorded as a non-invasive stress indicator. Ventilation rates were visualised from behind screens to avoid visual disturbance, and a minimum of three 15 second measures were recorded over 2 minutes after the 30 minute recovery to provide an average of beats per minute. Inter-observer reliability tests were conducted between the two observers for behavioural scoring to ensure repeatability/validity of results. One hour after treatment, fish were humanely killed by concussion and a blood sample obtained immediately and assayed for cortisol as described below.

\section{Experiment 3 - Condition place avoidance}

Individual tanks were split into two equal halves by dividers made from transparent Perspex $(445 \times 300 \times 3 \mathrm{~mm})$ with space for a door $(175 \times 125 \mathrm{~mm})$, and 24 holes $(2 \mathrm{~cm}$ diameter) evenly spaced in two vertical rows of six on either side of the door, in order to permit water flow to both sides of the tank. The door was attached by wire to a pulley system such that the door could be opened and closed without any disturbance to the fish. The tank environments were enriched with gravel, plants and air stones identically on both sides of the dividers. Fish (average weight \pm SE $138.10 \pm 12.80 \mathrm{~g} ; n=37$ ) were randomly assigned to one of seven anaesthetic treatment groups (five fish per group): benzocaine, etomidate, eugenol, MS-222, and 2-phenoxyethanol, and six fish for undisturbed and sham. For 2 weeks, fish were 
conditioned to associate the inflow side with a positive experience by being fed twice daily in that area of the tank only, whilst the other side remained neutral. Fish were checked twice a day, and once individuals entered the positive area prior to the presentation of food repeatedly over six consecutive days, it was assumed that the fish were conditioned to that side. The inflow or positive area was on the left hand side in half of the tanks and on the right in the other half to control for any left:right bias. Once conditioned, fish were anaesthetised in the home tank using enough drug to treat the entire tank (100 L; Table 1). The concentrations were chosen based on those recommended in Sneddon (2012), Neiffer and Stamper (2009), Ross and Ross (2008), reflecting those commonly used in laboratory practise for O. mykiss anaesthesia. The anaesthetic was added to the positive side either by airline tubing and a 50 $\mathrm{ml}$ syringe or a $1 \mathrm{~L}$ measuring cylinder, depending on the volume used, at the same time as feeding and fish were left to reach deep plane anaesthesia so the potential aversive exposure to the drug was coupled to a positive reward in order to gauge how negative an anaesthetic was. They were then carefully netted and transferred into $10 \mathrm{~L}$ opaque buckets with cover containing continuously aerated system water for 1 hour to recover. During this time the anaesthetic-treated water was removed from the home tank to eliminate all residues, and replaced with fresh filtered mains water used as inflow to the system, which had been aerated via airline and air stone for a minimum of 24 hours to ensure chlorine was not present. The water was at the same temperature as the system water $\left(12{ }^{\circ} \mathrm{C} \pm 1{ }^{\circ} \mathrm{C}\right)$ as were all water quality parameters $(\mathrm{pH} 7.2$, nitrite $<0.1 \mathrm{ppm}$, nitrate $<20 \mathrm{ppm}$, ammonia $<0.1 \mathrm{ppm})$. After 1 hour, the fish were returned to their tanks on the neutral side, with the door closed. Two litres of water were taken from the recovery buckets to determine the amount of cortisol released across the gills during the procedure and thereby providing a non-invasive comparative measure of circulating blood cortisol levels in the fish from each treatment immediately after exposure to the anaesthetic. Direct measurement of blood cortisol at this stage in the procedure would have required venepuncture and this procedure could have confounded the subsequent detection of between-treatment differences arising from the anaesthetic treatments. Fish were left to recover for 30 minutes and then latency to return to the positive side was tested; used here as a measure of the negative affective component of experiencing anaesthesia and a delay to return demonstrates how aversive the anaesthetic was for the individual. The door was opened and one pellet of food was added initially, and then every minute. The latency for the fish to enter the positive/conditioned side, as well as the latency to resume feeding response was recorded. Sham treated fish underwent the same procedure except were not exposed to an anaesthetic, and undisturbed treated fish were conditioned but 
not exposed to anaesthetic or relocation to the bucket. In order to understand the degree of stress associated with exposure to the anaesthetics during the condition place avoidance paradigm, terminal plasma samples were taken. Fish were humanely killed by concussion 1 $\mathrm{hr}$ after originally returning them to their tanks and a blood sample obtained immediately and assayed for cortisol as described below.

Blood

Sampling

All fish were humanely killed at approximately the same time each day (12:30 hours $\pm 1 \mathrm{hr})$ to ensure interpretation of plasma cortisol concentrations were not compromised by diel variations in cortisol secretion (Pickering and Pottinger, 1983). Fish were weighed, and blood was collected via sterile heparinised needles (25 g) into $2 \mathrm{ml}$ syringes. After centrifugation at $3500 \mathrm{x} \mathrm{g}$, at $4{ }^{\circ} \mathrm{C}$ for $5 \mathrm{~min}$, the supernatant plasma was frozen and stored at $-20{ }^{\circ} \mathrm{C}$ until further analysis. Cortisol concentrations were determined blind using a validated radioimmunoassay procedure (Pottinger and Carrick, 2001).

\section{Water extraction for cortisol analysis}

Water samples $(2.0 \mathrm{~L})$ underwent solid phase extraction (SPE) using Sep-Pak C-18 cartridges (Waters, UK) fitted to a four-port manifold. Water samples were pre-filtered through 0.45 micron nitrocellulose filters (diameter $15 \mathrm{~cm}$ ) (Whatman, UK) using a Buchner funnel and flask under vacuum, to remove any particles that might obstruct the cartridges. Cartridges were first primed by washing $5 \mathrm{ml}$ HPLC grade methanol through the cartridge at a rate of 2 $\mathrm{ml}$ per minute by a Gilson Minipuls 2 peristaltic pump, followed by a $5 \mathrm{ml}$ wash with distilled water. The water sample collected was then passed through the cartridge at the same rate. Finally, cartridges were washed with $5 \mathrm{ml}$ of distilled water to purge the salts and were flushed with air before being stored at $-20{ }^{\circ} \mathrm{C}$ until further analysis. The cartridges were eluted with $2.0 \mathrm{ml}$ of ethyl acetate and cortisol concentrations were determined blind in 200 $\mu \mathrm{l}$ of eluate using a validated radioimmunoassay procedure (Pottinger and Carrick, 2001).

\section{Statistical analysis}

All analyses were performed in Minitab v17 (Minitab, 2013) and all data, unless stated otherwise, met the assumptions for parametric analyses. In order to identify the most human anaesthetic for euthanasia and anaesthesia with recovery, we tested whether treatment had any effect on time to onset of anaesthesia, time to absence of consciousness and reflex responsiveness, and time to death by applying One-way ANOVAs with treatment as a factor. 
Data for time to absence of tail pinch from the Recovery experiment was not normally distributed and thus a non-parametric Kruskal-Wallis analysis was applied. Mann-Whitney U tests including sequential Bonferroni treatment for multiple tests were subsequently applied to compare between treatment groups. To determine the least behaviourally aversive anaesthetic, we tested whether treatment influenced latency to return to the positive/conditioned side and to resume feeding response, as data were not normally distributed a non-parametric Kruskal-Wallis test was applied. A chi-squared goodness of fit test was used to determine if treatment affected the stress response displayed during anaesthesia and to compare each anaesthetic with the results of sham handling. To assess whether treatment had an effect on plasma and water-borne cortisol concentrations One-way ANOVAs were employed with treatment as a factor. To test for an association between the concentrations of cortisol released into the water of the recovery bucket, following anaesthesia in the home tank, and the level of plasma cortisol at the end of the experiment, a Pearson correlation was applied to the data. Spearman rank correlations were applied to determine if there was an association between behavioural signs of aversion (latency to return to conditioned side and resume feeding) and plasma or water-borne cortisol concentrations.

\section{Results}

\section{Experiment 1 - Euthanasia}

Excluding the concussion treatment group, there was no effect of treatment on time to death $\left(F_{4,20}=2.18, p=0.109\right)$. For the anaesthetics, there was a treatment effect on the reciprocally transformed time to absence of equilibrium $\left(F_{4,20}=4.73, p<0.01\right.$; Table 3$)$, with fish exposed to benzocaine taking significantly longer than those exposed to 2-phenoxyethanol and etomidate (Tukey HSD: both $p<0.05$ ). However, the time taken for fish to lose reflex responsiveness to a tail pinch was not different between treatments $\left(F_{4,20}=0.81, p=0.536\right.$; Table 3).

The time required for low opercular beat rate (OBR) to become evident $\left(F_{4,20}=6.41, p<\right.$ 0.01; Table 3) and for OBR to cease completely $\left(F_{4,20}=3.28 ; p<0.05\right.$; Table 3$)$ was significantly different between treatments. Fish exposed to MS-222 took significantly longer to reach the low OBR threshold compared to those exposed to 2-phenoxyethanol, benzocaine, etomidate and eugenol (Tukey HSD: all $p<0.05$ ) and longer to cease OBR than fish exposed to etomidate (Tukey HSD: $p$ < 0.05). There was also a treatment effect on the tachy (rapid) OBR $\left(F_{4,18}=4.62, p=0.01\right.$; Table 3$)$ with fish exposed to benzocaine having considerably 
greater tachy OBR than those exposed to etomidate (Tukey HSD: $p<0.01$ ). For tachy OBR, both 2-phenoxyethanol and eugenol treatment group statistics are based on samples sizes of 4 as one fish from each did not exhibit this stage.

There was no treatment effect on reciprocally transformed plasma cortisol concentrations measured in blood samples collected immediately following euthanasia $\left(F_{5,25}=1.08, p=\right.$ 0.394; Fig. 6).

\section{Experiment 2 - Recovery}

Mean OBR 30 minutes after recovery from anaesthesia was significantly different between treatments $\left(F_{6,28}=8.26, p<0.001\right.$; Fig. 1$)$ with the mean OBR being lower in the undisturbed treatment group than all other groups with the exception of the etomidateexposed fish (Tukey HSD: all $p<0.05$ ). However, sham handling also resulted in a higher OBR than undisturbed controls and none of the anaesthetic-exposed groups exhibited OBR higher than the sham treatment group.

Time to absence of equilibrium was significantly different between the treatment groups $\left(F_{4}\right.$, $20=4.02, p<0.05$; Fig. 2), with etomidate-exposed fish taking considerably longer to enter light anaesthesia compared to fish exposed to eugenol (Tukey HSD: $p<0.05$ ). The time required to lose reflex responsiveness to a tail pinch was also affected by drug $(n=25 ; d f=4$; $H=16.56, p<0.01$; Fig. 3) with etomidate-exposed fish requiring longer than the fish exposed to any other anaesthetic (all $W=40.0, p=0.0122$ ).

There was a treatment effect on behavioural stress response during induction of anaesthesia $\left(X^{2}=488 ; d f=3 ; p<0.001\right.$; Fig. 4$)$. In response to the anaesthetics, only one fish exposed to benzocaine and 2-phenoxyethanol displayed fast swimming (category 3) and none in category 4. In contrast, one fish treated with etomidate, MS-222 and eugenol displayed category 4 where fish swam erratically continuously and leaped from the water. Additionally, four fish from each of the treatment groups benzocaine, MS-222 and 2-phenoxyethanol displayed category 2 or lower.

Plasma cortisol concentrations 60 mins after removal from the anaesthetic were not significantly different between treatment groups $\left(F_{6,28}=2.30, p=0.062\right.$; Fig. 5 and 6), 
although all treatments, including the sham treatment, were elevated compared to the undisturbed group.

\section{Experiment 3 - Condition place avoidance}

Following anaesthesia, there were no differences between treatment groups in the latency of return to the positive conditioned side $(n=25 ; d f=4 ; H=3.00, p=0.558$; Table 4$)$ or in the time taken to resume feeding $(n=25 ; d f=4 ; H=2.48, p=0.648$; Table 4).

There was a significant effect of treatment on plasma cortisol concentrations $\left(F_{6,30}=4.83, p\right.$ $<0.01$; Fig. 6), with plasma cortisol concentrations in MS-222-exposed fish being significantly elevated compared to fish exposed to 2-phenoxyethanol and eugenol (Tukey HSD: both $p<0.05), 2$ hrs after removal from the anaesthetic. The square root transformed rate of release of cortisol to water during the period in which the fish were exposed to anaesthetic also varied significantly between anaesthetic treatment groups $\left(F_{5,23}=10.64, p<\right.$ 0.001; Fig. 7). The cortisol release rate was significantly greater in fish exposed to 2phenoxyethanol compared to fish exposed to MS-222, benzocaine or sham treatment (Tukey HSD: both $p<0.01)$. There was no association between latency to return to conditioned side and cortisol (plasma: $\mathrm{r}_{\mathrm{s}}=-0.028, p=0.893$; water: $\mathrm{r}_{\mathrm{s}}=0.074, p=0.725$ ), and likewise with latency to resume feeding response and cortisol (plasma: $\mathrm{r}_{\mathrm{s}}=-0.188, p=0.368$; water borne: $\left.\mathrm{r}_{\mathrm{s}}=0.137, p=0.514\right)$. However, there was a weak negative association between plasma cortisol and the rate of release of cortisol to water $(\mathrm{r}=-0.444, p<0.05)$.

A summary of results across the three studies are shown in Table 5.

\section{Discussion}

The present study employed stress and behavioural indicators in rainbow trout to investigate the relative impact on welfare indicators of commonly used anaesthetics at concentrations reflective of common practice. The results suggest that anaesthetics differentially affected behaviour and physiology and that this information can be used to inform decisions as to which anaesthetic to employ for euthanasia and recovery anaesthesia at the concentrations investigated. Based upon time to reach light anaesthesia and low OBR, reduced plasma cortisol concentrations and low behavioural stress 2-phenoxyethanol may be a more humane alternative for use on rainbow trout, although note sample sizes are low. However, importantly it is not known whether this drug has analgesic properties so it may not be 
suitable for invasive procedures. This could be addressed by employing 2-phenoxyethanol in combination with an analgesic such as morphine (injected $5 \mathrm{mg} / \mathrm{kg} \mathrm{IM}$; Mettam et al. 2011). In contrast MS-222 and benzocaine are thought to act as local anaesthetics and may provide pain relief (Sneddon, 2012) thus careful consideration should be given in the context of the use of the fish and the role anaesthesia plays. Further work is also necessary to evaluate the analgesic properties of the different anaesthetics as well as the potential benefits associated with combination anaesthesia (Schoettger et al. 1970; Kumlu and Yanar, 1999; Yanar and Kumlu, 2001) particularly when anaesthesia is used for surgical or other invasive procedures.

\section{Euthanasia}

For the purpose of euthanasia in fish, the method of concussion offers advantages and is probably a less stressful and more humane alternative to anaesthetic agents. Primarily concussion is very rapid, and avoids prolonged exposure to chemicals and any potential side effects that might be incurred. However this method requires specific training to ensure that the procedure is carried out humanely according to The Animals (Scientific Procedures) Act 1986 guidelines (ASPA, 2012). In addition, the size of fish being sampled adds a level of complexity. If the fish is large achieving a rapid endpoint can be difficult, and with small fish there is the risk of compromising tissue collection. There was no evidence of a stress response during the process of anaesthesia in any of the treatment groups directly following euthanasia demonstrated by the low mean plasma cortisol concentrations (range 1.3 - $4.9 \mathrm{ng}$ ml-1). When comparing between the anaesthetic drugs, induction was slower for benzocaine (absence of equilibrium) and for MS-222 (cessation of opercular beat rate). Although two different concentrations were used in this study, it was only the higher dose of etomidate and 2-phenoxyethanol that induced more rapid times to mild and deep plane anaesthesia. This may be due to uptake rates and mode of action of these agents and requires further study. For the purposes of humane killing if rapid induction is key to ensuring a rapid death the results suggest that at the concentrations used, 2-phenoxyethanol and etomidate may be the preferred agents.

\section{Recovery}

If length of exposure is considered as a negative event, etomidate seemed to be the most disruptive, since it required the longest induction times for fish to reach both light and deep plane anaesthesia. Faster induction rates would mean that the impact of a potentially stressful event could be minimised while also limiting the contact time with the drug. However, there 
is a trade off with induction rates as they need to be sufficient in length so that the stage of anaesthesia can be controlled and monitored (Sneddon, 2012). Also whilst higher concentrations of anaesthetics would induce rapid induction times they may be aversive or detrimental to fish physiology and can result in accidental overdose (Sneddon, 2012).

Using OBR, a measure often used as a non-invasive indicator of stress, our results suggest that use of four of the five anaesthetic agents (benzocaine, MS-222, 2-phenoxyethanol and eugenol) as well as sham handling resulted in higher OBR compared to fish receiving no treatment. Yet the use of etomidate did not significantly elevate OBR and plasma cortisol values were lower than MS-222, benzocaine and eugenol. This might imply that at the concentration tested etomidate is least aversive, in terms of its effects on ventilation rate, and which is in line with recommendations by Readman et al. (2013) that etomidate is the most humane anaesthetic in zebrafish, Danio rerio. However, etomidate can suppress the HPI axis in fish (Limsuwan et al. 1983; Olsen et al. 1995). Negative effects on respiration and circulation have previously been reported in Chinook salmon (O. tshawytscha) anaesthetised using the nonbarbiturate hypnotic metomidate, an analog of etomidate (Hill and Forster, 2002 ; 2004). Therefore, the lack of elevation in OBR in trout may not be indicative of a nonaversive anaesthetic, but instead may be due to the pharmacological effects of etomidate. Therefore, using OBR as an indicator of stress during anaesthesia could be confounded, by direct effects of the drug on ventilation rate. The action of etomidate should be further tested in rainbow trout and other species, however, caution should also be applied when using etomidate as it is a hypnotic, acting to sedate the fish and it has no known intrinsic analgesic properties. Additionally, it is important to note that in the present study the sham treatment with no anaesthesia did elicit a comparable physiological stress response to that observed in the anaesthesia treatment groups. Indeed, among the sham-treated fish recovery OBR was similar to most anaesthetic groups as was plasma cortisol. Therefore, it is likely that confinement in a novel environment, the bucket in the present study, for anaesthesia, and the associated handling and transfer, is stressful in itself and should be avoided where practically possible. Comparisons between home tank anaesthesia and removal to another tank or vessel are rare yet many of the guidelines available propose fish should be anaesthetised in their home tank if possible.

Rainbow trout expressed varied behavioural responses in reaction to the anaesthetic agents. 
None of the fish from the sham, benzocaine and 2-phenoxyethanol treatment groups exhibited a response of the highest category (4), implying that these treatments may be least aversive in terms of behavioural reactions during anaesthesia. In contrast, fish in the other anaesthetic treatment groups (etomidate, eugenol and MS-222) exhibited erratic swimming and breaking the surface of the water. Therefore these drugs could be considered to have an adverse effect on behaviour and elicit behavioural stress in trout during induction. Rainbow trout anesthetised by immersion in $\mathrm{CO}_{2}$ are reported to show a similar strong aversive response of rapid swimming and escape attempts for at least 30 seconds (Kestin et al. 1995). The mechanisms of action should be investigated further to determine if it is the olfactory or gustatory characteristics of the anaesthetic that comprises the negative affective experience driving these stress-related behaviours. Certainly, fish are known to avoid, or to attempt to escape from, negative stimuli (Sneddon, 2009) and jumping from the water in the bucket may be motivated by an aversion or avoidance response. Investigation into recovery anaesthesia in the home tank could remove this possible confounding factor (Caamaño Tubío et al. 2009), or enriched experimental buckets could be used (gravel, plants and cover) to establish if stress responses vary after anaesthesia in a barren bucket, as data suggests certain stress indicators are ameliorated in enriched environments in rainbow trout (Pounder et al. 2016). Do note the sample sizes for this experiment were relatively low and future studies should increase the number of individuals used.

\section{Condition place avoidance}

In accordance to the findings in rainbow trout (Readman et al. 2017), in the present study anaesthesia was not aversive to rainbow trout in terms of influencing latencies to return to a previously conditioned area or resume feeding response. This may be because anaesthesia via immersion is not aversive enough for a feeding response to be disrupted, particularly for species such as rainbow trout, which are bred and selected for high growth rates for industry, meaning that they are highly motivated to feed. However, it is worth noting that Readman, Owen et al. (2017) used $50 \%$ of effective dose seen within the literature in their experiments and as such may not have been enough to illicit avoidance behaviour, whereas in this present study we used concentrations that induce anaesthesia and thus reflective of common practice. Many studies investigating fish behaviour or for the application of anaesthesia/euthanasia protocols it is often required for fish to be taken from home tanks and placed into test arenas or other holding vessels. Our results with the sham-treated fish clearly show that placing fish into a novel environment is stressful in itself and have additive effects of stress that may have 
been associated with handling or novel environments (Blaser and Gerlai, 2006; Levin et al. 2007; Caamaño Tubío et al. 2009). Fish may be less anxious in their home tank and react differently to anaesthesia than would be the case in the more stressful context of being caught, handled and placed in a novel environment. The possibilities that conditioned place avoidance does not work when performed in the home tank or that the drugs used here are not aversive to rainbow trout cannot be excluded but further work is necessary to clarify these issues.

In contrast to the behavioural responses, plasma cortisol concentrations were greatest in the MS-222 treatment group, and were significantly higher than levels in the 2-phenoxyethanol, eugenol and undisturbed treatment groups, suggesting that MS-222 exposure resulted in the most persistent adverse effects of all the drugs at the concentrations evaluated. We also analysed free cortisol from water samples taken from the buckets in which fish were placed to recover. Cortisol released across the gills provides an alternative measure of the activity of the HPI axis during and following exposure to a stressor (Scott and Ellis, 2007; Ellis et al. 2005). The water-borne cortisol concentrations were not directly proportional to plasma concentrations of cortisol, but instead showed a broadly inverse relationship with plasma cortisol levels. This appears counter-intuitive, but the two endpoints report different aspects of stress axis function, with plasma cortisol providing a snapshot of levels at the precise time of sampling, whereas the water-borne cortisol concentration provides information on the activity of the stress axis for the entirety of the recovery period. It is possible that in the group exposed to MS-222, factors controlling the stress response were more profoundly affected than in other groups, resulting in an attenuation of the stress response, lower plasma cortisol levels and hence lower release rates to water for the duration of the anaesthesia. However, on recovery and regaining consciousness, other aspects of the MS-222 exposure may have been perceived as more stressful by the MS-222-treated fish, resulting in a greater post-anaesthesia cortisol response.

\section{Overview}

The results of the present study suggest that 2-phenoxyethanol at the concentrations tested might be a preferred anaesthetic for use in rainbow trout. The time required to reach light anaesthesia and low OBR was less compared to several of the other anaesthetics tested during the euthanasia experiment, and plasma cortisol concentrations were lowest in the recovery and condition place avoidance experiments suggesting a less stressful experience. In addition, 
the majority (80\%) of fish in this treatment group demonstrated a lower behavioural stress score indicating either calm swimming or no movement on immersion into the anaesthetic and suggestive of a less aversive response. If we assume these indicators are linked to improved welfare and reduced stress during anaesthesia then 2-phenoxyethanol would be preferred over the other anaesthetics at the concentrations tested in the present study. In rainbow trout, 2-phenoxyethanol has already been identified as an effective anaesthetic (Gilderhus and Marking, 1987), with fungicidal and bactericidal characteristics making it particularly useful during surgery (Jolly et al. 1972; Ucar and Atamanalp, 2010). It is relatively harmless to fish in terms of its acute toxicity (Velíšek and Svobodová, 2004), and has been shown to have no effect on haematological parameters (Tort et al., 2002; Ucar and Atamanalp, 2010; Velíšek et al. 2007) or amine concentrations in the brain (Sloley et al. 1986). However it must be noted that side effects arising from 2-phenoxyethanol exposure have also been reported in fish although not necessarily in rainbow trout. These include reduced immune function, impaired ventilation, reduced cardiovascular responses, lowered blood $\mathrm{O}_{2}$, increased $\mathrm{CO}_{2}$, and reduced pH (Iwama et al. 1989; Lambooij et al. 2009; Ortuño et al. 2002; Sneddon 2012). More research is required however, as the pharmacological action of 2-phenoxyethanol is currently undetermined, although it is thought to involve expansion of neuronal cell membranes (Burka et al. 1997).

Concentrations of each anaesthetic employed in the study reflect common laboratory practice (Neiffer and Stamper, 2009; Ross and Ross, 2008; Sneddon, 2012) but ideally a range of concentrations with increased sample sizes should be tested for each anaesthetic agent, in order to establish if it is the agent itself that may be aversive, or if it is due to the concentration in which it is administered. Time and resource constraints meant that this was not possible, and therefore results should be taken to be applicable only to the concentrations that were tested. Further, we have only explored the acute effects of these agents and it would be vital to assess longer term behavioural and physiological function to truly understand the chronic impact of anaesthesia.

The different mechanisms of action and the purpose for anaesthesia should be considered with importance when selection of an anaesthetic with least adverse effects associated with its use is being considered. The anaesthetic agents that were tested have different functional properties. For instance, MS-222 and benzocaine are structurally similar compounds, and are often used in veterinary medicine as topical analgesics and have local anaesthetic qualities 
(Sneddon, 2012). Therefore, if fish are being anaesthetised for surgery, or for possible invasive procedures that may cause tissue damage, then benzocaine or MS-222 may be the most humane agents to use. Studies with zebrafish found anaesthesia with MS-222 had no effect on behaviour (Nordgreen et al. 2014), emphasising the need for the effects of anaesthetic on behaviour and physiology in different species to be investigated, to identify the most appropriate agent for each species across a variety of procedures.

Our research suggests that 2-phenoxyethanol at the concentrations used is likely to be the least aversive anaesthetic in rainbow trout when non-invasive procedures are applied during anaesthesia. However, further research is needed that includes: the utilization of other experimental designs such as choice chambers, investigation with a range of agent concentrations for different procedures during anaesthesia, and establishing the effect of environmental enrichment, in order to confidently recommend the anaesthetic agents that promote welfare in rainbow trout. Another factor to consider is that only MS222 is approved for veterinary use in aquaculture in the USA and Europe, therefore, 2-phenoxyethanol would need to meet regulatory standards for food safety and public health before its use can be adopted. However, we recommend it for veterinary health and for research purposes based on the results from the two recommended concentrations investigated. This initial study has shown that anaesthetics do affect rainbow trout physiology and behaviour and may do so adversely, therefore highlighting the need for further research into the effects of anaesthesia and the interaction of environment and anaesthetic dosage for different purposes of anaesthesia.

\section{Acknowledgements}

LS is grateful for a Research Grant (NC/K000888/1) from the National Centre for the 3Rs (NC3Rs) UK and JM was supported by Society of Biology Summer Studentship from the Society for Endocrinology. We are grateful to André Barbas, James Whitfield, Samantha Evans and Jonathan Buckley for technical assistance. 


\section{References}

ASPA, 2012. The Animals (Scientific Procedures) Act 1986 Amendment Regulations 2012.

Blaser, R., Gerlai, R., 2006. Behavioral phenotyping in zebrafish: Comparison of three behavioral quantification methods. Behav. Res. Methods. 38, 456-469.

Burka, J.F., Hammell, K.L., Horsberg, T.E., Johnson, G.R., Rainnie, D.J., Speare, D.J., 1997. Drugs in salmonid aqualculture - a review. J. Vet. Pharmacol. Ther. 20, 333-349.

Caamaño Tubío, R.I., Weber, R.A., Aldegunde, M., 2009. Home tank anesthesia: a very efficient method of attenuating handling stress in rainbow trout (Oncorhynchus mykiss, Walbaum): short communication. J. Appl. Ichthyol. 26, 116-117.

Cotter, P.A., Rodnick, K.J., 2006. Differential effects of anesthetics on electrical properties of the rainbow trout (Oncorhynchus mykiss) heart. Comp. Biochem. Physiol. Part A: Mol. Integr. Physiol. 145, 158-165.

Cressey, D., 2014. Fish-kill method questioned. Nature.506, 419-420.

Cuesta, A., Meseguer, J., Esteban, M.A., 2004. Total serum immunoglobin m levels are affected by immunomodulators in seabream (Sparus aurata L.). Vet. Immunol. Immunopathol. 101, 203210.

Ellis, T., James, J.D., Stewart, C., Scott, A.P., 2004. A non-invsive stress assay based upon measurement of free cortisol released into the water by rainbow trout. J. Fish Biol. 65, 12331252.

Ellis, T., James, J.D., Scott, A.P., 2005. Branchial release of free cortisol and melatonin by rainbow trout. J. Fish Biol. 67, 535-540.

Europa, 2015. http://eur-lex.europa.eu/legal-content/EN/TXT/?uri=CELEX:52013SC0497. Date accessed: 28/03/16.

FEAP, 2014. European Aquaculture Production Report.

Frost, A.J., Thomson, J.S., Smith, C., Burton, H.C., Davis, B., Watts, P.C., Sneddon, L.U., 2013. Environmental change alters personality in the rainbow trout, Oncorhynchus mykiss. Anim Behav 85, 1199-1207.

Frost, A.J., Winrow-Giffen, A., Ashley, P.J., Sneddon, L.U., 2007. Plasticity in animal personality traits: does prior experience alter the degree of boldness? P Roy Soc B-Biol Sci 274, 333-339.

Gilderhus, P.A., Marking, L.L., 1987. Comparative efficacy of 16 anesthetic chemicals on rainbow trout. North Amer. J. Fish Manag. 7, 288-292.

Gilmour, K.M., DiBattista, J.D., Thomas, J.B., 2005. Physiological causes and consequences of social status in salmonid fish. Integr Comp Biol 45, 263-273.

Hill, J.V., Forster, M.E., 2002. The effects of fish anaesthetics (MS222, metomidate and AQUI-S) on heart ventricle, the cardiac vagus and branchial vessels from Chinook salmon (Oncorhynchus tshawytscha). Fish Physiol. Biochem. 27, 19-28.

Hill, J.V., Forster, M.E., 2004. Cardivascular responses of Chinook salmon (Oncorhynchus tshawytscha) during rapid anaesthetic induction and recovery. Comp. Biochem. Physiol. 137, 167-177.

HomeOffice, 2014. Annual Statistics of Scientific Procedures on Living Animals Great Britain 2014.

Holloway, A.C., Keene, J.L., Noakes, D.G., Moccia, R.D., 2004. Effects of clove oil and MS-222 on blood hormone profiles in rainbow trout Oncorhynchus mykiss, Walbaum. Aquac. Res. 35, 1025-1030.

Iwama, G.K., McGeer, J.C., Pawluk, M.P., 1989. The effects of 5 fish anesthetics on acid base balance, hematocrit, blood-gases, cortisol, and adrenaline in rainbow trout. Can. J. Zool. 67, 2065-2073.

Jolly, D.W., Mawdesley, L.E., Bucke, D., 1972. Anaesthesia of fish. Vet. Rec. 91, 424-426.

Keene, J.L., Noakes, D.L.G., Moccia, R.D., Soto, C.G., 1998. The efficacy of clove oil as an anaesthetic for rainbow trout, Oncorhynchus mykiss (Walbaum). Aquac. Res. 29, 89-101.

Kestin, S., Wotton, S., Adams, A., 1995. The effect of $\mathrm{CO}_{2}$, concussion or electrical stunning of rainbow trout (Oncorhunchus mykiss) on fish welfare, in: Svennevig, N., Krogdahl, Å. (Eds.), Quality in Aquaculture. European Aquaculture Society, Belgium, pp. 380-381.

Kumlu M, Yanar M: Effects of the anaesthetic quinaldine sulphate and muscle relaxant diazepam on sea bream juveniles (Sparus aurata). Isr J Aquacult 51:143-147, 1999 
Lambooij, B., Pilarczyk, M., Bialowas, H., Reimert, H.G.M., Andre, G., Vis, J.W. van de., 2009. Anaesthetic properties of propiscin (etomidate) and 2-phenoxyethanol in the common carp (Cyprinus carpio L.), neural and behavioural measures. Aquac. Res. 40, 1328-1333.

Levin, E.D., Bencan, Z., Cerutti, D.T., 2007. Anxiolytic effects of nicotine in zebrafish. Physiol. Behav. 90, 54-58.

Lewbart, G.A., 1998. Answer 224, Self-assessment colour review of ornamental fish, Manson Publishing. The Veterinary Press., London, pp. 154.

Limsuwan, C., Limsuwan, T., Grizzle, J.M., Plumb, J.A., 1983. Stress response and blood characteristics of Channel catfish (Ictalurus punctatus) after anesthesia with etomidate. Can. J. Fish Aquat. Sci. 40, 2105-2112.

Mettam, J.J., Oulton, L.J., McCrohan, C.R., Sneddon, L.U., 2011. The efficacy of three types of analgesic drugs in reducing pain in the rainbow trout, Oncorhynchus mykiss. Appl. Anim. Behav. Sci. 133, 265-274.

Minitab, 2013. Minitab Statistical Software, Release 17 for windows, State College, Pennsylvania. Minitab ${ }^{\circledR}$ is a registered trademark of Minitab, Inc.

Neiffer, D.L., Stamper, M.A., 2009. Fish Sedation, Anesthesia, Analgesia, and Euthanasia: Considerations, Methods, and Types of Drugs. Ilar J. 50, 343-360.

Nordgreen, J., Tahamtani, F.M., Janczak, A.M., Horsberg, T.E., 2014. Behavioural Effects of the Commonly Used Fish Anaesthetic Tricaine Methanesulfonate (MS-222) on Zebrafish (Danio rerio) and Its Relevance for the Acetic Acid Pain Test. PLOS One. 9.

Olsen, Y.A., Einarsdottir, I.E., Nilssen, K.J., 1995. Metomidate Anesthesia in Atlantic Salmon, Salmo-Salar, Prevents Plasma-Cortisol Increase during Stress. Aquac. 134, 155-168.

Ortuño, J., Esteban, M.A., Meseguer, J., 2002. Effects of phenoxyethanol on the innate immune system of gilthead sea bream (Sparus aurata L.) exposed to crowding stress. Vet. Immunol. Immunopathol. 89, 29-36.

PFMA, 2015. Pet Population Report.

Pickering, A.D., Pottinger, T.G., 1983. Seasonal and diel changes in plasma cortisol levels of the brown trout, Salmo trutta L. Gen. Comp. Endocrinol. 49, 232-239.

Pickering, A.D., Pottinger, T.G., 1989. Stress Responses and Disease Resistance in Salmonid Fish Effects of Chronic Elevation of Plasma-Cortisol. Fish Physiol. Biochem. 7, 253-258.

Pirhonen, J., Schreck, C.B., 2003. Effects of anaesthesia with MS-222, clove oil and $\mathrm{CO}_{2}$ on feed intake and plasma cortisol in steelhead trout (Oncorhynchus mykiss). Aquac. 220, 507-514.

Pottinger, T.G., Carrick, T.R., 2001. Stress responsiveness affects dominant-subordinate relationships in rainbow trout. Horm. Behav. 40, 419-427.

Pounder, K.C., Mitchell, J.L., Thomson, J.S., Pottinger, T.G., Buckley, J., Sneddon, L.U., 2016. Does environmental enrichment promote recovery froms stress in rainbow trout? Appl. Anim. Behav. Sci. 176, 136-142.

Readman, G.D., Owen, S.F., Murrell, J.C., Knowles, T.G., 2013. Do Fish Perceive Anaesthetics as Aversive? PLOS One. 8.

Readman, G.D., Owen, S.F., Knowles, T.G, Murrell, J.C., 2017. Species specific anaesthetics for fish anaesthesia and euthanasia. Sci. Rep. 7.

Ross, L.G., Ross, B., 2008. Anaesthetic and sedative techniques for aquatic animals. Blackwell Science Ltd., London.

Schoettger, R.A., Julin, A.M., 1967. Efficacy of MS-222 as an anesthetic on four salmonids. US Fish Wildl. Serv.

Schoettger RA, Steucke EW: Synergic mixtures of MS-222 and quinaldine as anesthetics for rainbow trout and northern pike. Prog Fish-Cult 32:202-205, 1970

Scott, A.P., Ellis, T., 2007. Measurement of fish steroids in water-a review. Gen. Comp. Endocrinol. $153,392-400$.

Sloley, B.D., Hickie, B.E., Dixon, D.G., 1986. The effect of sodium pentachlorophenate, diet and sampling procedure on amine and tryptophan concentrations in the brain of rainbow trout, Salmo gardneri Richardson. J. Fish Biol. 28, 267-277.

Sneddon, L.U., 2003. The bold and the shy: individual differences in rainbow trout. J. Fish Biol. 62, 971-975.

Sneddon, L.U., 2009. Pain Perception in Fish: Indicators and Endpoints. Ilar J. 50, 338-342. 
Sneddon, L.U., 2011. Cognition and Welfare, in: Brown, C., Laland, K., Krause, J. (Eds.), Fish Cognition and Behaviour, Wiley-Blackwell, pp. 405-434.

Sneddon, L.U., 2012. Clinical anesthesia and analgesia in fish. J. Exot. Pet Med. 21, 32-43.

Sneddon, L.U., Braithwaite, V.A., Gentle, M.J., 2003. Novel object test: Examining nociception and fear in the rainbow trout. J. Pain. 4, 431-440.

Thorgaard, G.H., Bailey, G.S., Williams, D., Buhler, D.R., Kaattari, S.L., Ristow, S.S., Hansen, J.D., Winton, J.R., Bartholomew, J.L., Nagler, J.J., Walsh, P.J., Vijayan, M.M., Devlin, R.H., Hardy, R.W., Overturf, K.E., Young, W.P., Robison, B.D., Rexroad, C., Palti, Y., 2002. Status and opportunities for genomics research with rainbow trout. Comp. Biochem. Physiol. B. 133, 609-646.

Thomson, J.S., Watts, P.C., Pottinger, T.G., Sneddon, L.U., 2011. Physiological and genetic correlates of boldness: Characterising the mechanisms of behavioural variation in rainbow trout, Oncorhynchus mykiss. Horm Behav 59, 67-74.

Thomson, J.S., Watts, P.C., Pottinger, T.G., Sneddon, L.U., 2012. Plasticity of boldness in rainbow trout, Oncorhynchus mykiss: do hunger and predation influence risk-taking behaviour? Horm Behav 61, 750-757.

Tort, L., Puigcerver, M., Crespo, S., Padró, F., 2002. Cortisol and haematological response in sea bream and trout subjected to the anaesthetics clove oil and 2-phenoxyethanol. Aquac. Res. 33, 907-910.

Ucar, A., Atamanalp, M., 2010. The effects of natural (clove oil) and synthetical (2-phenoxyethanol) anesthesia substances on hematology parameters of rainbow trout (Oncorhynchus mykiss) and brown trout (Salmo trutta fario). J. Anim. Vet. Adv. 9, 1925-1933.

USDA, 2013. https://speakingofresearch.files.wordpress.com/2008/03/usda-animal-research-use2011-13.pdf. Date accessed: 28/03/16.

Velíšek, J., Svobodová, Z., Piačková, V., 2007. Effects of 2-phenoxyethanol anaesthesia on haematological profile on common carp (Cyprinus carpio) and rainbow trout (Oncorhynchus mykiss). Acta. Vet. Brno. 76, 487-492.

Velíšek, J., Svobodová, Z., 2004. Anaesthesia of rainbow trout (Oncorhynchus mykiss) with 2phenoxyethanol: acute toxicity and biochemical blood profile. Acta. Vet. Brno. 73, 379-384.

Wong, D., von Keyserlingk, M.A.G., Richards, J.G., Weary, D.M., 2014. Conditioned Place Avoidance of Zebrafish (Danio rerio) to Three Chemicals Used for Euthanasia and Anaesthesia. PLOS One. 9.

Yanar M, Kumlu M: The anaesthetic's effects of quinaldine sulphate and/or diazepam on sea bass (Dicentrarchus labrax) juveniles. Turk J Vet Anim Sci 25:185-189, 2001

Zahl, I.H., Samuelsen, O., Kiessling, A., 2012. Anaesthesia of farmed fish: implications for welfare. Fish Physiol. Biochem. 38, 201-218. 


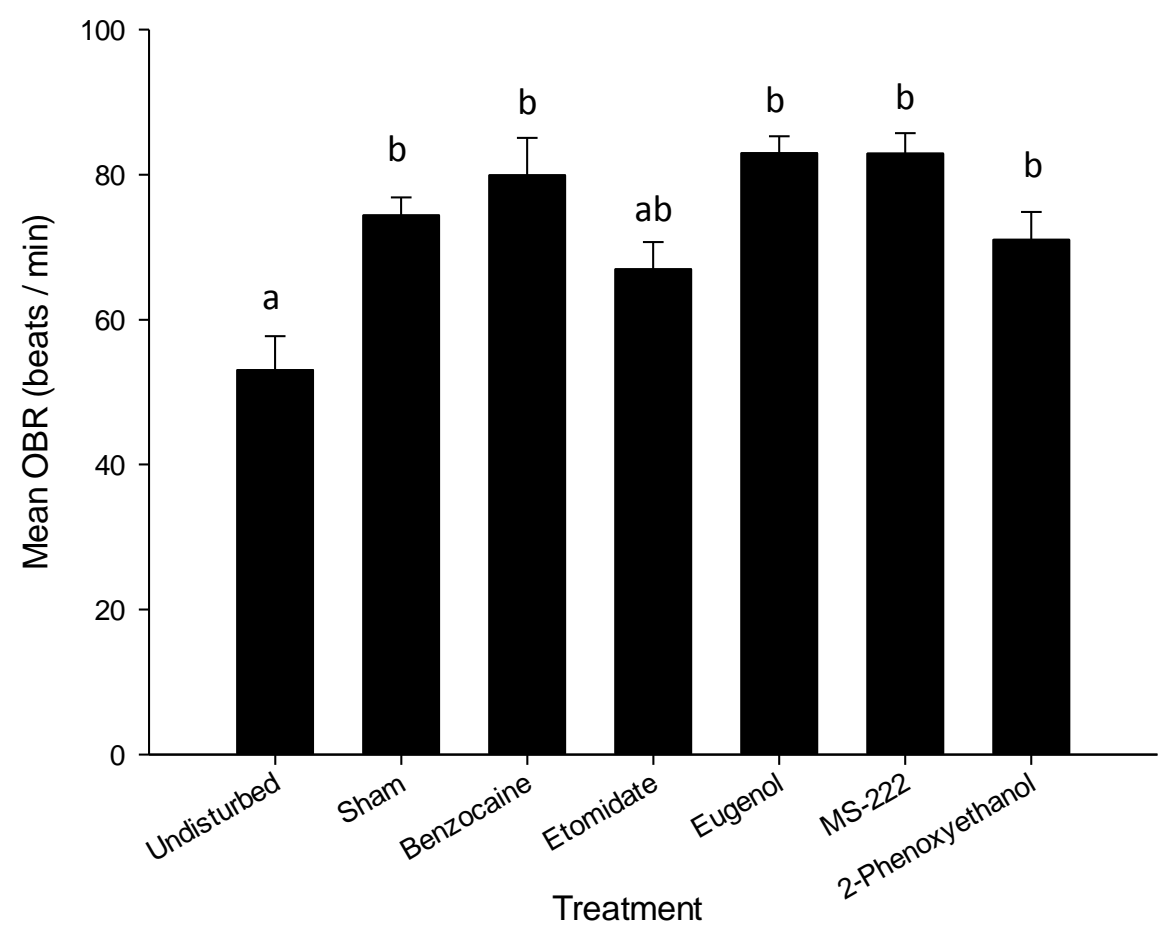

Figure 1. Mean (+ SE) opercular beat rate (beats $\min ^{-1}$ ) 30 mins after removal from anaesthetic, in rainbow trout. Means that do not share a common lower case letter were significantly different ( $p<0.001 ; n=5$ per group).

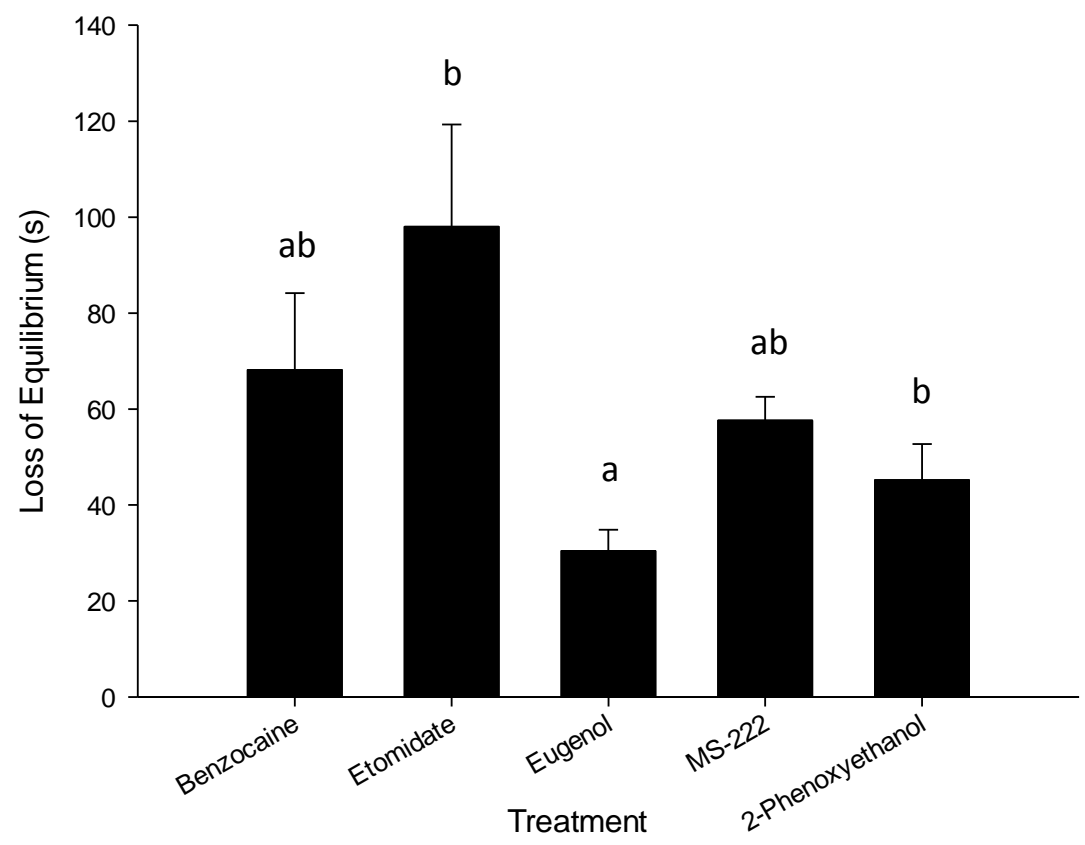


Figure 2. Mean (+ SE) time (seconds) to absence of equilibrium (mild plane anaesthesia) in rainbow trout following immersion in an anaesthetic solution. Means that do not share a common lower case letter are significantly different ( $p<0.05 ; n=5$ per group).

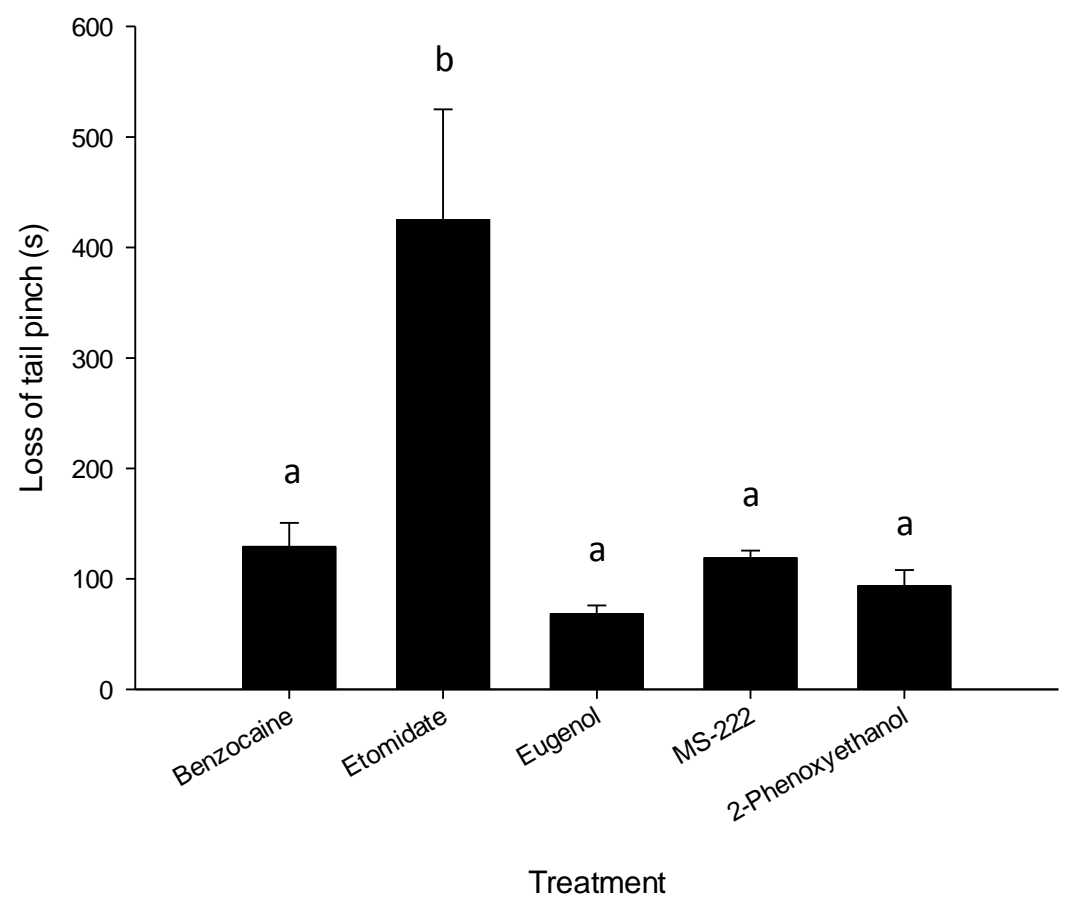

Figure 3. Mean (+ SE) time (seconds) to absence of the tail pinch response (deep plane anaesthesia) in rainbow trout following immersion in anaesthetics. Means that do not share a common lower case letter are significantly different ( $p<0.01 ; n=5$ per group). 


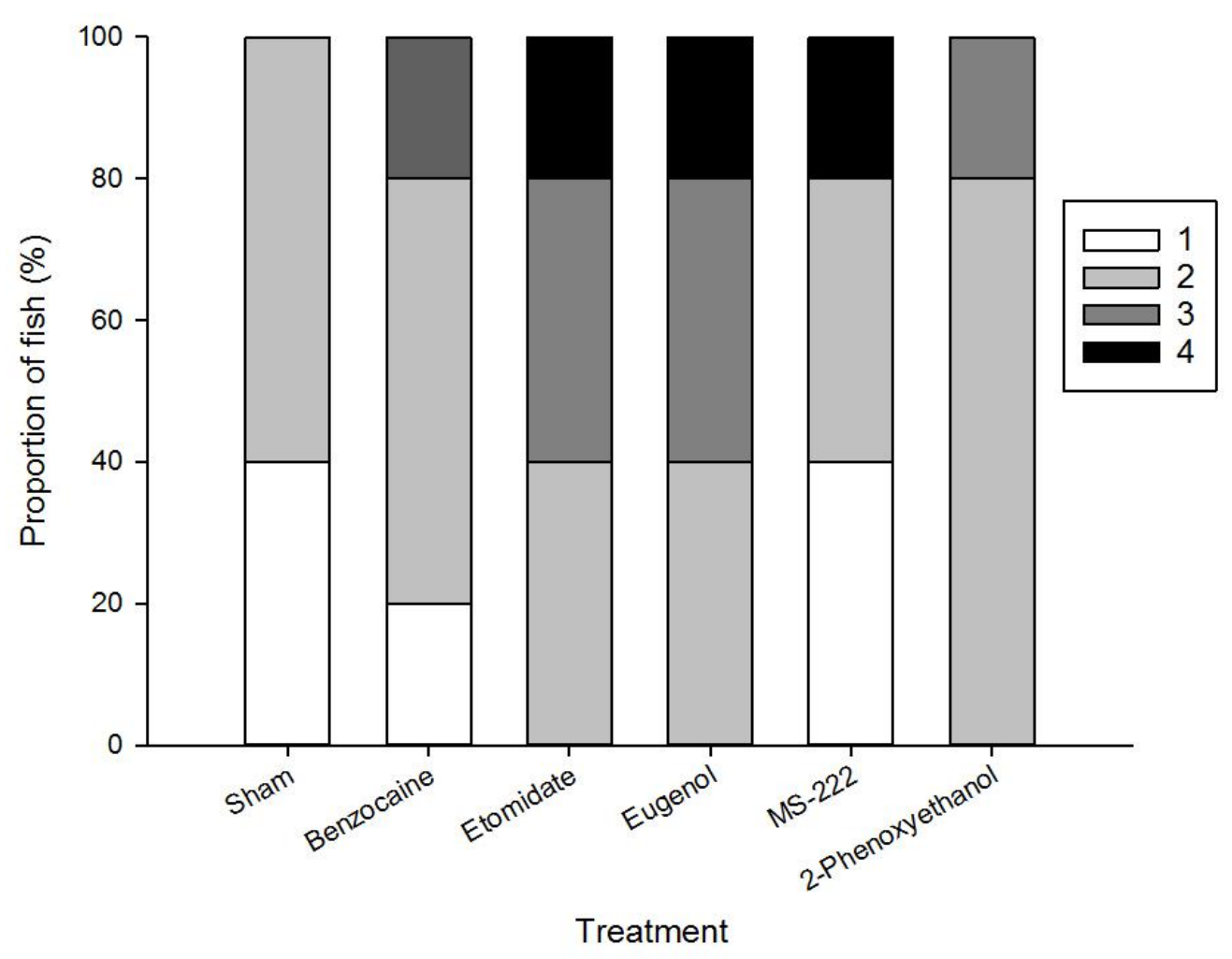

Figure 4. Proportion of each behavioural stress response expressed during anaesthesia in rainbow trout exposed to anaesthetic-treated system water from the point of immersion to absence of tail pinch responsiveness $\left(X^{2}=488 ; n=5\right.$ per group). The stress indicator scoring system was as follows: $1=$ no movement, $2=$ calm swimming, 3 = sporadic erratic swimming and $4=$ constant erratic swimming. 
A)

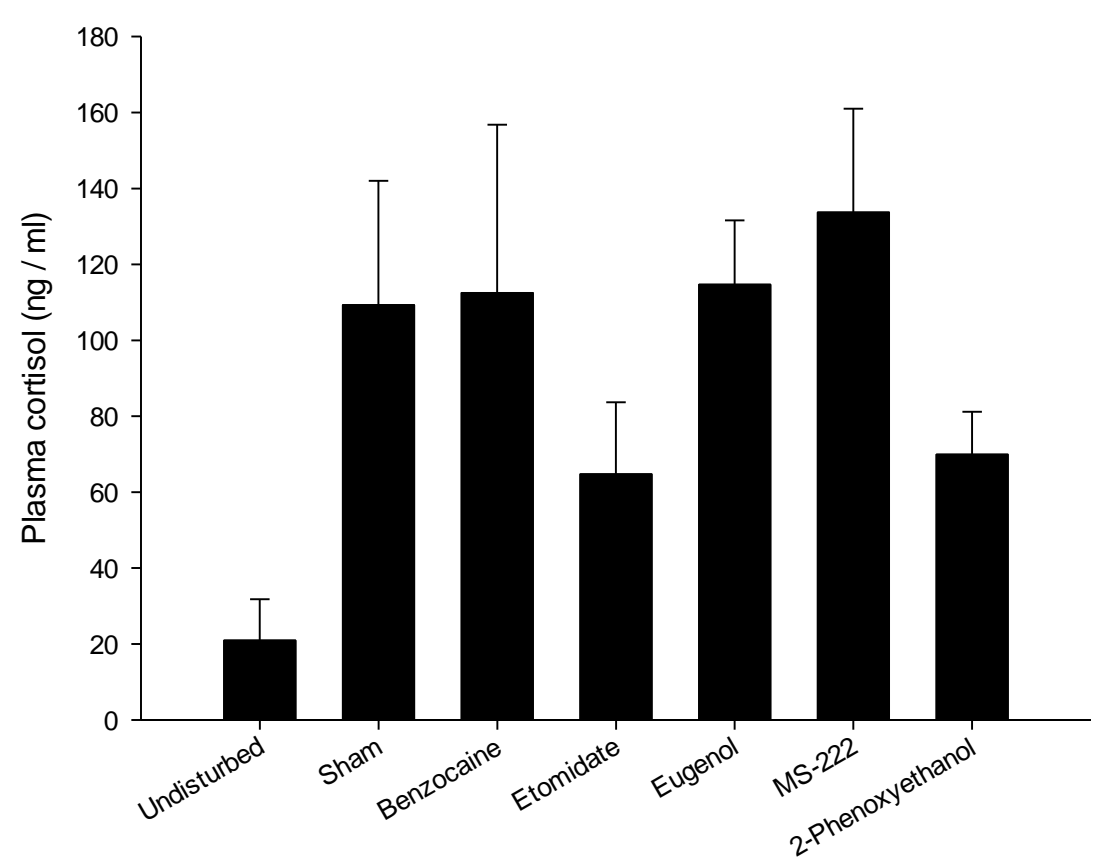

Treatment

B)

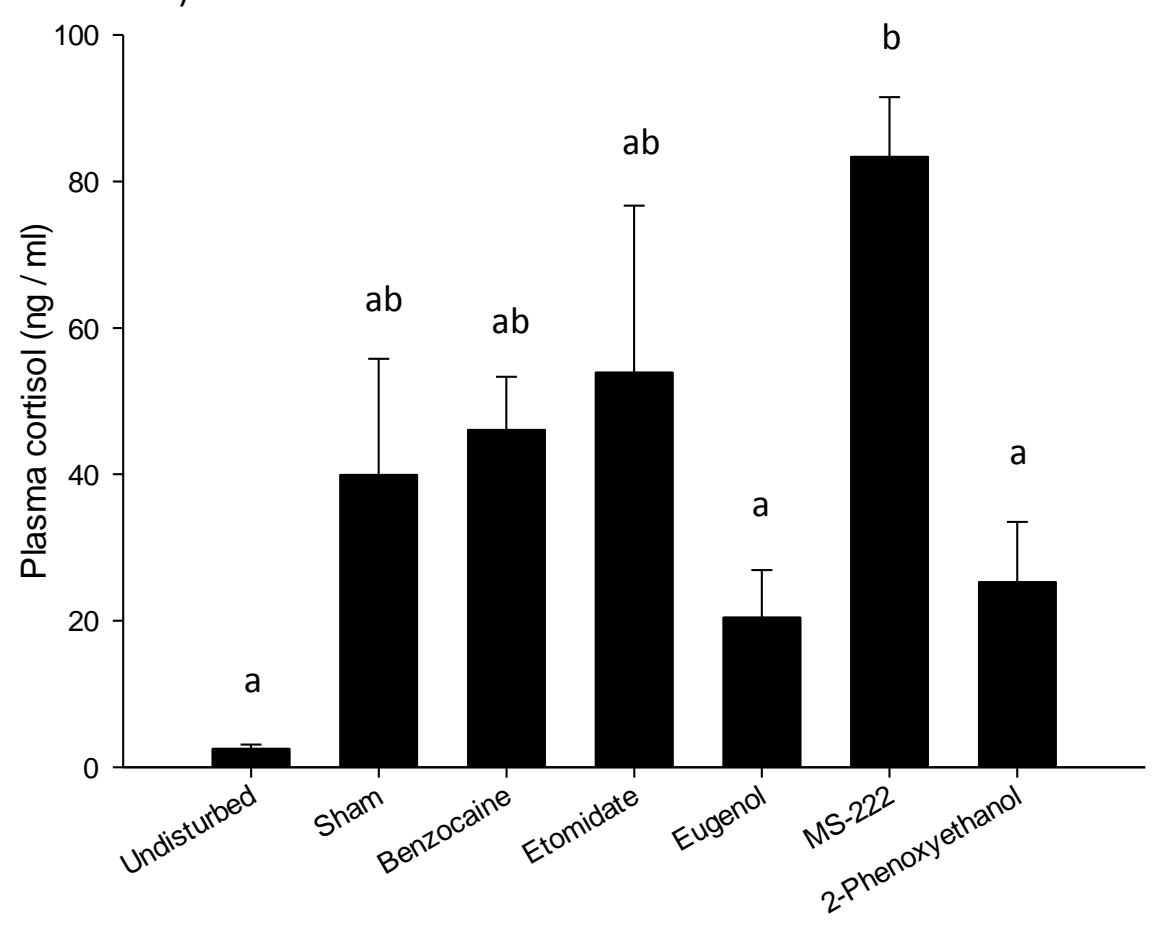

Treatment

Figure 5. Mean $(+\mathrm{SE})$ plasma cortisol concentrations $\left(\mathrm{ng} \mathrm{m}^{-1}\right)$ in rainbow trout, $(\mathrm{A})$ one hour after deep plane anaesthesia ( $n=5$ per group), and (B) two hrs after deep plane anaesthesia in the home tank ( $n=5$ per anaesthetic group, and $n=6$ for sham and undisturbed treatments). Means that do not share a common lower case letter are significantly different $(p<0.05)$. 


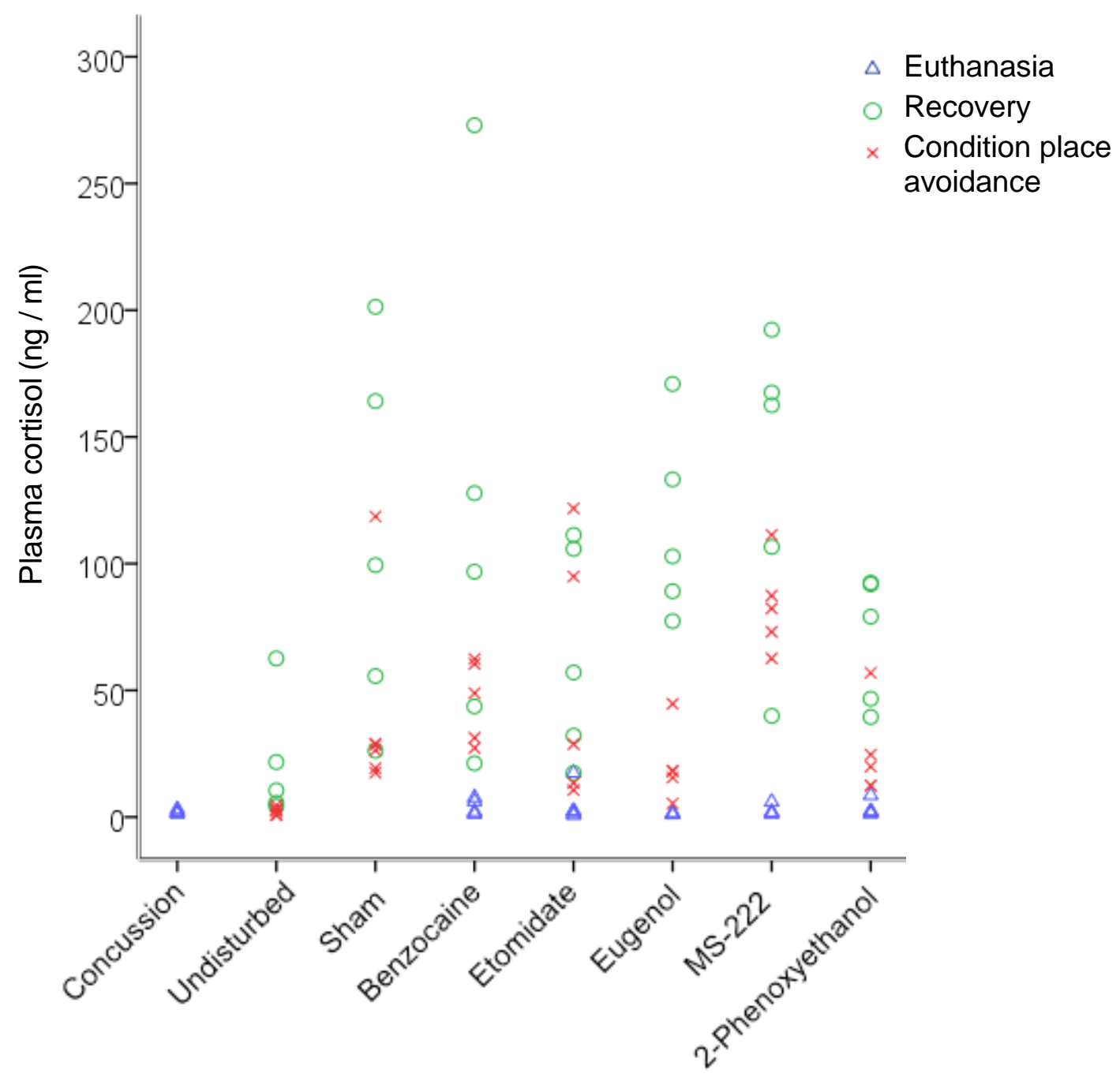

Figure 6. Comparison of individual plasma cortisol concentrations $\left(\mathrm{ng} \mathrm{ml}^{-1}\right)$ in rainbow trout following euthanasia with anaesthetic (open triangles), recovery from deep plane anaesthesia (open circles), or subjected to a conditioned place avoidance paradigm (crosses). 


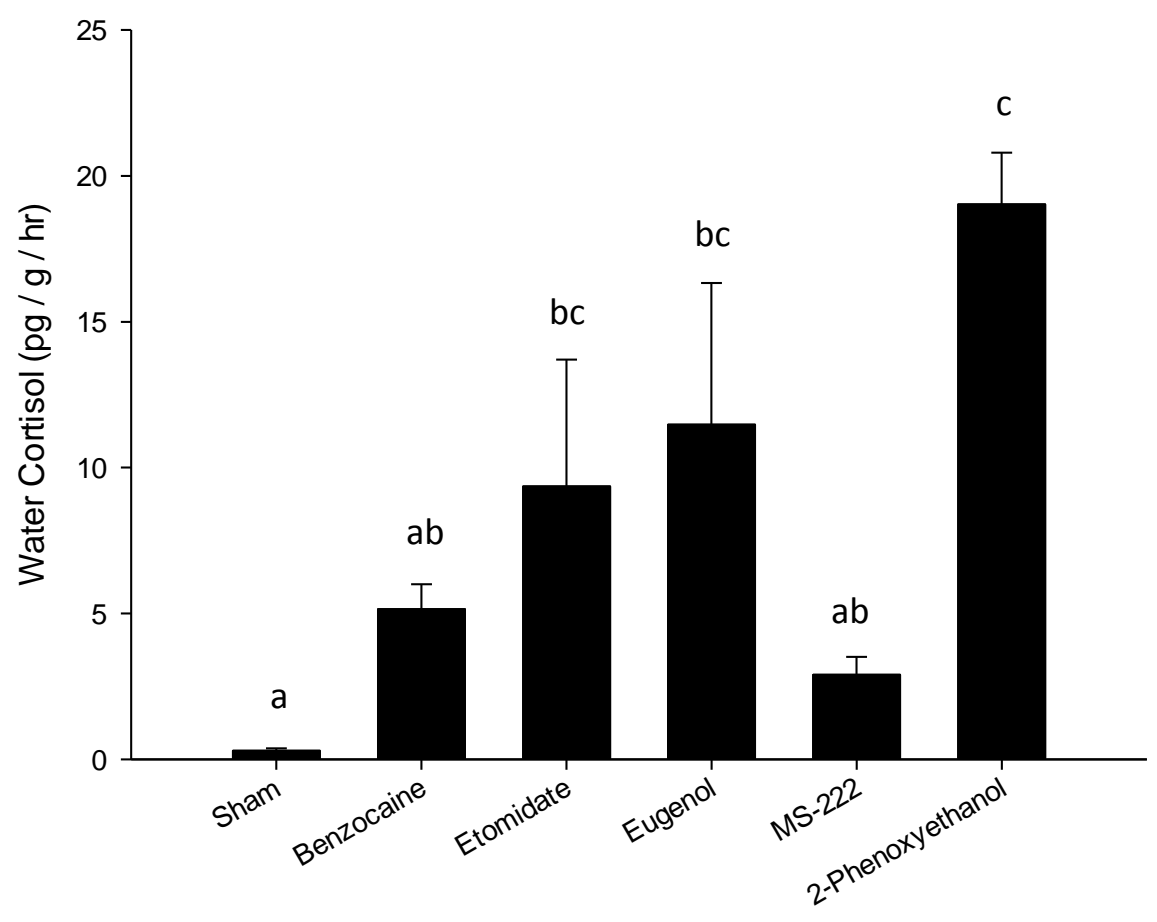

Treatment

Figure 7. Mean (+ SE) water cortisol concentrations $\left(\mathrm{pg} \mathrm{g}^{-1} \mathrm{hr}^{-1}\right)$ collected from recovery buckets one hour after deep plane anaesthesia in the home tank, in rainbow trout. Means that do not share a common lower case letter were significantly different $(p<0.01 ; n=5$ per anaesthetic group, and $n=4$ for sham treatment). 
Table 1. Summary of selected anaesthetic agents and concentrations used in this study (Neiffer and Stamper, 2009; Ross and Ross, 2008; Sneddon, 2012; T. G. Pottinger, unpub.

Level of

\begin{tabular}{lll} 
Anaesthesia & Measure & Definition \\
\hline Excitation & Tachy (faster than normal) OBR & Increased ventilation rate \\
Light & Absence of equilibrium & Failure to maintain upright position \\
Deep & $\begin{array}{l}\text { Low OBR } \\
\text { Absence of reflex activity and presumably consciousness } \\
\text { Absence of OBR }\end{array}$ & $\begin{array}{l}\text { Infrequent gill ventilation movements } \\
\text { Absence of reflex responsiveness to a tail pinch } \\
\text { Absence of ventilatory movements }\end{array}$ \\
& Death & $\begin{array}{l}\text { Cessation of OBR and heart beat } \\
\text { Overdose }\end{array}$
\end{tabular}

data).

Table 2. Summary of selected measures used in this study. Tachy opercular beat rate (OBR) and time to reach each of the following was measured for each fish.

\begin{tabular}{llll}
\multirow{2}{*}{ Anaesthetic } & \multicolumn{2}{c}{ Concentration } & \multirow{2}{*}{ Supplier } \\
\cline { 2 - 4 } & Euthanasia $\left(\mathbf{L}^{-\mathbf{1}}\right)$ & Recovery/Aversion $\left(\mathbf{L}^{-\mathbf{1}}\right)$ & \\
\hline Benzocaine & $150 \mathrm{mg}$ & $33 \mathrm{mg}$ & Sigma-Aldrich Co., UK \\
Etomidate & $10 \mathrm{mg}$ & $2 \mathrm{mg}$ & Thomson \& Joseph Ltd, UK \\
Eugenol & $200 \mathrm{mg}$ & $100 \mathrm{mg}$ & Sigma-Aldrich Co., UK \\
MS-222 (buffered) & $200 \mathrm{mg}$ & $100 \mathrm{mg}$ & Sigma-Aldrich Co., UK \\
2-Phenoxyethanol & $6 \mathrm{ml}$ & $0.5 \mathrm{ml}$ & Vetark Professional, UK
\end{tabular}


Table 3. Mean ( \pm SE) induction measurements (seconds) and plasma cortisol concentrations (ng / ml) recorded for each treatment group during euthanasia (absence of equilibrium failure to maintain upright position; tachy opercular beat rate - increased ventilation rate, low OBR - rare gill movements; absence of tail pinch - absence of reflex activity and presumably consciousness; absence of OBR - absence of ventilation rate). Different superscripts denote significant difference.

\begin{tabular}{|c|c|c|c|c|c|c|c|c|c|c|c|c|c|c|}
\hline \multirow{2}{*}{ Treatment } & \multicolumn{2}{|c|}{$\begin{array}{l}\text { Absence of } \\
\text { equilibrium } \\
\text { (s) }\end{array}$} & \multicolumn{2}{|c|}{$\begin{array}{l}\text { Tachy } \\
\text { OBR } \\
\text { (beats per } \\
\text { minute) }\end{array}$} & \multirow{2}{*}{$\begin{array}{l}\begin{array}{l}\text { Low } \\
\text { (s) }\end{array} \\
\text { Mean }\end{array}$} & \multirow{2}{*}{$\begin{array}{l}\text { OBR } \\
\text { SE }\end{array}$} & \multicolumn{2}{|c|}{$\begin{array}{l}\text { Absence of } \\
\text { tail pinch (s) }\end{array}$} & \multicolumn{2}{|c|}{$\begin{array}{l}\text { Absence } \\
\text { OBR (S) }\end{array}$} & \multicolumn{2}{|c|}{$\begin{array}{l}\text { Time } \\
\text { death (s) }\end{array}$} & \multicolumn{2}{|c|}{$\begin{array}{l}\text { Plasma } \\
\text { cortisol } \\
(\mathrm{ng} / \mathrm{ml})\end{array}$} \\
\hline & Mean & SE & Mean & SE & & & Mean & SE & Mean & SE & Mean & SE & Mean & SE \\
\hline Concussion & - & - & - & - & - & - & - & - & - & - & $14.0^{\mathrm{a}}$ & 3.7 & 2.0 & 0.3 \\
\hline Benzocaine & $53.8^{\mathrm{b}}$ & 10.7 & $101.2^{\mathrm{b}}$ & 5.6 & $79.0^{\mathrm{a}}$ & 8.9 & 86.6 & 4.3 & 101.6 & 8.3 & $176.6^{\mathrm{b}}$ & 24.5 & 3.7 & 1.4 \\
\hline Etomidate & $31.6^{\mathrm{a}}$ & 3.6 & $76.8^{\mathrm{a}}$ & 4.4 & $66.8^{\mathrm{a}}$ & 7.6 & 100.0 & 10.2 & $98.8^{\mathrm{a}}$ & 16.8 & $253.6^{\mathrm{b}}$ & 34.8 & 4.9 & 3.2 \\
\hline Eugenol & 32.0 & 1.3 & 91.5 & 1.5 & $67.2^{\mathrm{a}}$ & 7.4 & 86.0 & 5.1 & 134.0 & 16.5 & $167.6^{\mathrm{b}}$ & 13.3 & 1.3 & 0.1 \\
\hline MS-222 & 46.6 & 8.4 & 89.8 & 2.5 & $122.4^{\mathrm{b}}$ & 13.2 & 91.4 & 14.2 & $163.2^{\mathrm{b}}$ & 14.2 & $277.2^{\mathrm{b}}$ & 45.7 & 2.5 & 0.9 \\
\hline $\begin{array}{l}\text { 2- } \\
\text { Phenoxyethanol }\end{array}$ & $27.8^{a}$ & 0.7 & 92.3 & 5.1 & $76.2^{\mathrm{a}}$ & 7.0 & 75.6 & 11.7 & 109.6 & 17.2 & $235.4^{\mathrm{b}}$ & 35.1 & 3.2 & 1.4 \\
\hline
\end{tabular}

Table 4. Mean \pm SE latencies to return to positively associated side and to resume feeding response (seconds) post treatment and recovery, in rainbow trout.

\begin{tabular}{|c|c|c|c|c|c|c|c|c|}
\hline \multirow[t]{2}{*}{ Treatment } & \multicolumn{2}{|c|}{$\begin{array}{l}\text { Latency to return to } \\
\text { positively associated } \\
\text { side (s) }\end{array}$} & \multicolumn{2}{|c|}{$\begin{array}{l}\text { Latency to resume } \\
\text { feeding response } \\
\text { (s) }\end{array}$} & \multicolumn{2}{|c|}{$\begin{array}{l}\text { Plasma cortisol (ng } \\
\text { / ml) }\end{array}$} & \multicolumn{2}{|c|}{$\begin{array}{l}\text { Water cortisol (pg } \\
\text { /g/hr) }\end{array}$} \\
\hline & Mean & SEM & Mean & SEM & Mean & SEM & Mean & SEM \\
\hline Undisturbed & - & - & - & - & 2.5 & 0.6 & - & - \\
\hline Sham & - & - & - & - & 39.9 & 15.9 & 0.29 & 0.09 \\
\hline Benzocaine & 250.0 & 147.0 & 250.0 & 147.0 & 46.1 & 7.3 & 5.1 & 0.9 \\
\hline Etomidate & 47.4 & 30.7 & 86.8 & 68.6 & 53.9 & 22.8 & 9.4 & 4.4 \\
\hline Eugenol & 31.8 & 23.3 & 63.8 & 23.3 & 20.4 & 6.5 & 11.5 & 4.9 \\
\hline $\begin{array}{l}\text { MS-222 } \\
2-\end{array}$ & 30.2 & 20.5 & 30.2 & 20.5 & 83.4 & 8.2 & 2.9 & 0.6 \\
\hline Phenoxyethanol & 94.8 & 41.7 & 100.0 & 40.4 & 25.3 & 8.2 & 19.0 & 1.8 \\
\hline
\end{tabular}


Table 5. Summary of mean responses for each anaesthetic across the three experiments: euthanasia with anaesthetic, recovery from deep plane anaesthesia, or subjected to a conditioned place avoidance paradigm. Different superscripts denote significant difference.

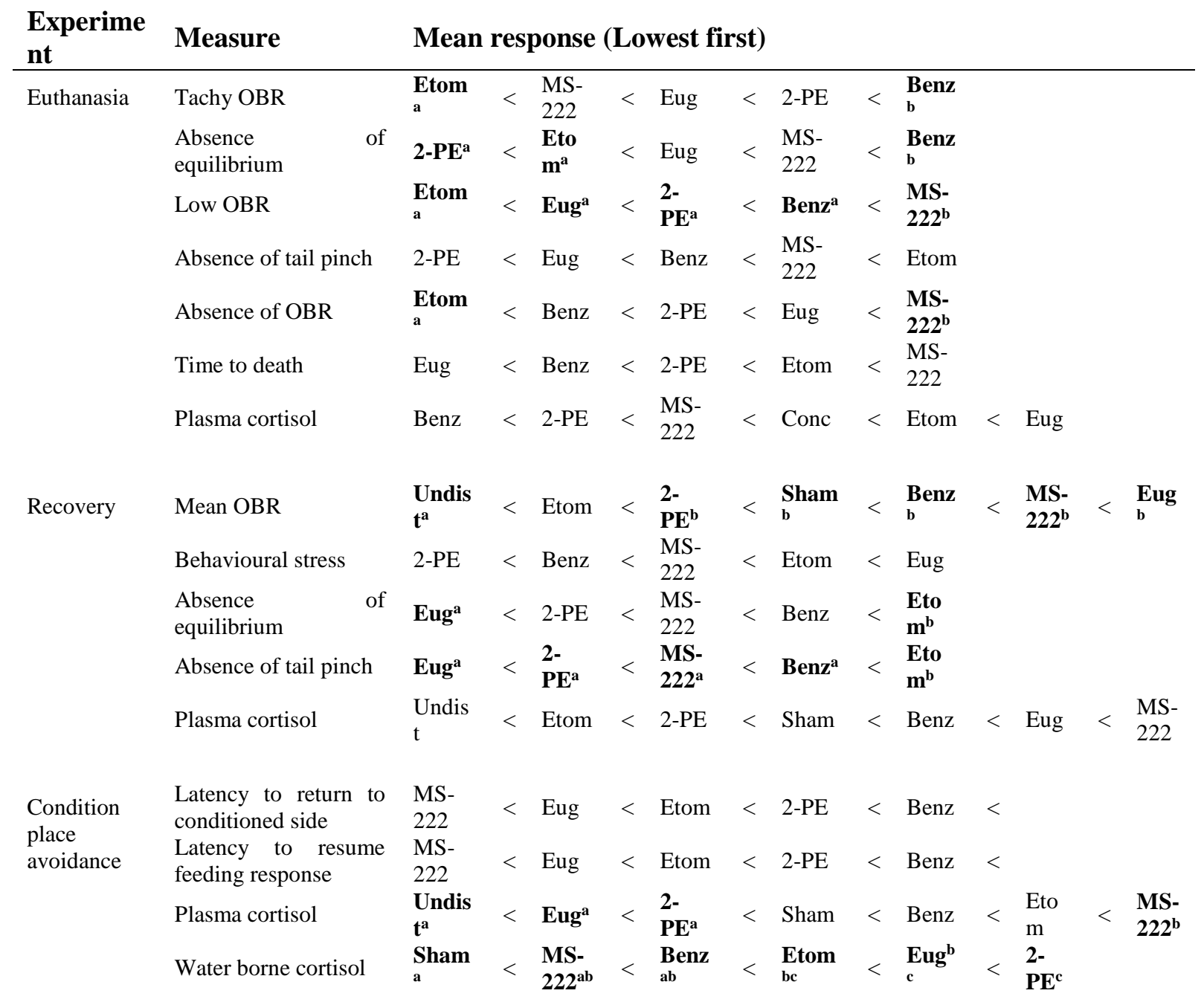

